\title{
Sentiment-Augmented Asset Pricing in Bursa Malaysia: A Time-Varying Markov Regime-Switching Model
}

\author{
Han Hwa Goh \\ Lee Lee Chong ${ }^{b}$ \\ Ming Ming Lai ${ }^{\mathrm{c}}$ \\ Multimedia University
}

\begin{abstract}
This paper examines the nonlinear effects of investor sentiment on asset pricing in Bursa Malaysia. The Fama and French three-factor model is re-augmented within a time-varying Markov regime-switching framework to investigate the three risk premiums, conditioned by four different proxies for investor sentiment (i.e. marketwide indicators). The study finds evidence that the stock returns movement of Bursa Malaysia exhibits a nonlinear two regimes pattern. Besides, changes in the investor sentiment to some extent function as a mediator in the regime switching dynamics between bear and bull market cycles in Malaysian stock returns. It is also found that an increase in positive sentiment of investors leads to a higher transition probability of regime switching during bear markets. In addition, the three risk premiums are timevariant, contingent upon the fluctuation of the proxies for investor sentiment within discrete regimes. The study finds that in general, the market premium falls when the stock market switches from bull to bear markets. On the contrary, both the size and value premiums increase when the stock market moves from bull to bear markets.
\end{abstract}

Keywords: Asset pricing, Bursa Malaysia, investor sentiment, time-varying Markov regime-switching model

JEL classification: G120, G410, C580

\section{Introduction}

Extreme market volatility in global financial markets is becoming more common. Such volatile fluctuations have been observed during the Brexit, U.S. presidency election, price drop in crude oil and more other world events in recent years. Chen, Tian and Zhao (2017) portrayed 2016 as the year of global black swan events. UK's Brexit (leaving the European Union) vote and Donald Trump's unexpected win in the US presidential election have caused the decline of several stock market indices in the

a Faculty of Management, Multimedia University, Persiaran Multimedia, 63100 Cyberjaya, Selangor Darul Ehsan, Malaysia. E-mail:hhgoh@mmu.edu.my (Corresponding author)

b Faculty of Management, Multimedia University, Persiaran Multimedia, 63100 Cyberjaya, Selangor Darul Ehsan, Malaysia. E-mail:Ilchong@mmu.edu.my

c Faculty of Management, Multimedia University, Persiaran Multimedia, 63100 Cyberjaya, Selangor Darul Ehsan, Malaysia. E-mail:mmlai@mmu.edu.my

Article Info: Received 25 April 2018; Revised 12 September 2018; Accepted 20 September 2018

https://doi.org/10.22452/MJES.vol55no2.8 
European financial markets and global financial markets over a short period of time. The Malaysian stock market is not isolated from such external shocks and coupled with the $1 \mathrm{MDB}$ scandal, investors' confidence deteriorated while the ringgit has been steadily declining over the past one and a half years, according to prominent Malaysian economist Jomo Kwame Sundaram (Idris \& Aziz, 2016). Up to date, no conventional finance theories, which perceive market to be rational, can fully explain the irrationalities of behaviour in the stock market. Standard asset pricing theories state that asset prices are determined purely by investors' unbiased cognitive evaluation and maximisation of expected utility, and there is no role for investor sentiment (Xu \& Green, 2013). However, behavioural theories claim that investors may hold fallacious stochastic beliefs, either with excessive optimism or pessimism, and therefore inaccurately estimate asset value; hence asset prices to digress from their intrinsic values (De Long, Shleifer, Summers, \& Waldmann, 1990; Kumar \& Lee, 2006; Lee, Shleifer, \& Thaler 1991). Positive sentiment spurs investors to be more confident about their competence to assess situations and thus more unhesitant to take risks; and vice versa (Kuhnen \& Knutson, 2011).

Asset valuations are vital for investors to determine the value of a firm and thus make an investment strategy. The capital asset pricing model (CAPM), propounded by Sharpe (1964) and Lintner (1965), claims that there is a positive effect of the market risk on the risk premium of financial assets. Nonetheless, CAPM does not reflect the share return actually obtained on the equity market (Reinganum, 1981; Rosenberg, Reid, \& Lanstein, 1985). As such, Fama and French three-factor (hereafter F-F) model (1993) is designed to augment the conventional CAPM by including two factors of firm size and book-to-market value. As evidenced by them in the US stock markets, the returns of stocks of small capitalisation and high book-to-market values are higher than those of the CAPM. There has subsequently been extensive empirical work carried out to evaluate the soundness of the F-F model, among others, Lawrence, Geppert and Prakash (2007); Simpson and Ramchander (2008). In recent years, Fama and French (2015) further developed a 5-factor model to explain average returns. However, the two new factors (profitability and investment) they have added to improve explanatory power are relatively recent discoveries which are premature and the research of these factors in different markets and time periods is still limited. Thus far, Fama-French 5 -factor model has been tested to Indian market (Harshita \& Yadav, 2015) and Japan market (Kubota \& Takehara, 2017) besides the U.S.

Investors' sentiment is ignored and not measured in traditional finance theories. Nevertheless, recent studies have shown that markets are sentiment driven (Baker, Wurgler, \& Yuan, 2012; Yang \& Zhang, 2014). Investors' sentiment drives asset values away from its fundamentals as evidenced by re-occurrence of market anomalies and financial turmoil. It is therefore important to quantify investors' sentiment and capture it in asset valuation in order to have efficient capital allocation and optimal cost of capital. However, very little research have been done in modelling asset pricing with investors' sentiment in emerging markets which are perceived to be young and underdeveloped with more noise traders compared to developed markets. 
Unlike those mature markets in developed countries, the Malaysian stock market, which is an emerging market, is inefficient in the weak form and significantly overreacts to surprises in economic crisis and political events (Ali, Nassir, Hassan, \& Abidin, 2010). The study of Lai, Tan and Chong (2013) also showed evidence with surveyed data that both the institutional and retail investors in Malaysia tend to overreact. The role of investor sentiment is pertinent in explaining market inefficiency. Positive sentiment encourages investors to take more risk as they have more confidence whereas negative sentiment will have the reverse impact (Kuhnen \& Knutson, 2011). The linkage between sentiment and stock return is hardly constant under different market circumstances (Karakatsani \& Salmon, 2008).

In the literature, investor sentiment consists of two measures, direct and indirect. While indirect measures are proxies from market data, direct measures are the surveyed data with direct contact with investors such as the American Association of Individual Investors (AAII) and Investor Intelligence (II) which are only available in the United States. We use the indirect measures in our study. Although there are a variety of proxies for sentiment measures suggested by the behavioural pricing literature, Baker and Wurgler (2006) stated that there are no uncontroversial and definitive measures of sentiments. Our choice of sentiment indicators has, to a large extent, been constrained by lack of data availability. As a result, we employ the following proxies: number and return of initial public offerings (i.e. NIPO and RIPO) as employed by Baker and Wurgler (2007), ratio of advancers to decliners (ADR) by Brown and Cliff (2004) and consumer sentiment index (CSI) by Chen (2011), Fisher and Statman (2003), Ho and Hung (2012), Hsu, Lin and Wu (2011), Jansen and Nahuis (2003), and Schmeling (2009).

The role of sentiment on stock prices remains vague in theory and disputable in empirical tests. This study is therefore crucial and timely in areas of asset valuation and portfolio management. In this study, we aim to utilise a time-varying Markov regimeswitching model to examine the risk premiums of the F-F model when we employ four different market sentiment proxies separately as a mediator of regime switches. We use the F-F model in our study as it is globally recognised as a useful description of stock returns. It is hoped that the empirical outcomes of this study offer an insightful view and are able to help investors in the stock market assess risk premiums and thus stock returns all the more precisely.

Overall, the contributions of this paper to the behavioural finance literature especially from the Malaysian perspective are in the following aspects. Firstly, we use a time-varying Markov-switching model to examine whether investor sentiment changes play a mediating role in explanation of regime-switching dynamics between bear and bull market cycles in Malaysian stock returns. Besides, we unearth the nonlinear association between stock return and three risk premiums of the F-F model. Lastly, we test directly the market sentiment proxies individually instead of a single composite index of sentiment as shown in most previous researches. The reasons for doing so are twofold: first to disclose dissimilarities in sentiment effects; and second, to circumvent the replication problem over time that is usually an issue whenever the principal components are employed to work out a composite index. The remainder of this paper is structured as follows. The following section presents the literature review 
while section 3 explains the data and methodology involved. Section 4 illustrates and discusses the empirical results and Section 5 concludes the findings.

\section{Literature Review}

The standard asset pricing theory explains that prices (and returns) of stocks should be equal or close to their expected fundamental values and the returns rely only on the cross-sectional systematic risks (Fama \& French, 1993, 1995, 2012, 2015). Fama and French (1993) utilised the overall market risk premium, size factor and book-to-market ratio to account for excess stock returns and they further developed a five-factor model to explain average returns in 2015.

A substantial body of empirical evidence in finance however reveals that stock returns persistently deviate from their fundamentals, and further discloses that investor sentiment affects the stock returns (Baker \& Wurgler, 2006, 2007; Kim \& Ha, 2010; Liao, Huang, \& Wu, 2011; Yang \& Zhang, 2014). Behavioural theories postulate that investors may develop erroneous beliefs and/or behavioural bias, either with undue optimism or pessimism, about the future distribution of returns on assets and subsequently inaccurately assess the asset values, causing anomalies of prices from their intrinsic values (De Long et al., 1990; Kumar \& Lee, 2006; Lee et al., 1991). Only limited studies have incorporated behavioural dimension in asset pricing models, among others, Shefrin and Statman (1994), Statman, Fisher and Anginer (2008), Xu and Green (2013) and Yang and Li (2013).

Prior empirical studies show that there is a significant influence of investor sentiment on stock returns due to limited arbitrage activities and investor irrationality. Ho and Hung (2009) indicated that the effectiveness of asset pricing models in explaining stock returns can be enhanced when investor sentiment is incorporated into modelling the dynamics of risk exposures. The impacts of investor sentiment on stock prices are studied by researchers in some countries who employ regression models with aggregate or industrial-level data (Chen, Chen, \& Lee, 2013; Schmeling, 2009; Zhang \& Semmler, 2009). Their empirical results have pointed to investor sentiment as the cardinal agent of nonlinear and asymmetric stock returns. The link between sentiment and stock returns is getting more complicated as suggested by mounting evidence. The minimal effects of sentiment on the stock return may well be varying between regimes of high and low sentiments (optimism and pessimism). Besides, McMillan (2003) and Lee and Chiu (2012) suggested that owing to the existence of market friction, cost of transaction, as well as the interactive behaviour of informed and 'noise' investors, the financial markets may exhibit behaviour of nonlinearity.

A review of literature reveals that most of the studies done are focussed on developed markets which have different market structure and characteristics as compared to emerging markets. Unlike those mature markets in developed countries, the Malaysian capital market (an emerging economy) overreacts to surprises in domestic political events and is influenced by external shocks such as SARS outbreak, September 11th terrorist attacksas cited by Ali et al. (2010). Schmeling (2009) revealed that the impacts of sentiment on stock returns are more substantial for a nation which has less market integrity or less efficient regulatory institutions. 


\section{Data and Methodology}

\subsection{Data}

In conducting empirical estimation, we collect the data on stocks which have been listed for at least a year and traded on main board of Bursa Malaysia over the period January 2001 to December 2015. The market sentiment proxy data is also collected over the same period. The firm and sentiment proxy data is largely taken from the data service providers, i.e. Datastream and Bloomberg Inc. The 1997 Asian financial crisis had caused the stock markets of South East Asian region to collapse. Although there is no specific date of full economic recovery, Angabini and Wasiuzzaman (2010) believed that the economy almost recovered by the middle of year 2000. Hence, the investigation of stock returns performance by adapting Fama and French three-factor model (1993) only starts in January 2001.

\subsection{Sentiment Proxies}

For lack of data availability, our choice of market sentiment proxies has to a large extent been constrained by the following: number and return of initial public offerings (i.e. NIPO and RIPO), ratio of advancers to decliners (ADR) and consumer sentiment index (CSI).

It is often assumed the underlying demand for initial public offerings (IPOs) is highly sensitive to investor sentiment. The prices of IPOs are normally put up after having consultation with investment bankers who are well-versed in market situations. Yet, the puzzle of IPOs being under-priced to such a great extent still remains unresolved. Meanwhile, the volatility of average first-day returns can be strongly linked to the number of IPOs and other proxies of sentiment that are not fundamentally related.

Brown and Cliff (2004) stated that the relative market robustness measured in buying-selling imbalance can be reflected through the ratio of advancers to decliners (ADR). The number of advancing issues (advancers) is referred to as the total number of shares in the Malaysian stock market whose closing prices at month-end are higher than their opening prices at the beginning of the month, while the number of declining issues (decliners) measures the opposite. In general, a larger value of the ADR indicates a broader base of an upward trend, and thus a stronger underlying sentiment of the market.

CSI is basically a fundamental indicator of economic sentiment. It has been issued by the Malaysian Institute of Economic Research (MIER) since 1988. This index is developed from quarterly surveys on over 1,200 domestic households. The range of questions in the survey covers the respondents' both contemporary and anticipated financial conditions, economic and job prospects as well as their purchase intention on houses and other major consumer durables. The CSI is also known as the consumer confidence index $(\mathrm{CCl})$, which has been gaining in popularity as one of the proxies of investor sentiment in the stock market. In recent years, there have been many empirical studies carried out in developed markets showing that $\mathrm{CCls}$ and stock returns are significantly related especially amid bear economic situations. 


\subsection{Empirical Model}

In the traditional Fama and French model, the expected excess returns on stock portfolios are a function of the portfolios' risk of three factors, i.e. the market, size and value premiums, which can be written as follows:

$$
R_{i, t}-R F R_{t}=\alpha_{i}+\beta_{i, 1}\left(R M_{t}-R F R_{t}\right)+\beta_{i, 2} S M B_{t}+\beta_{i, 3} H M L_{t}+e_{i, t}
$$

where $R_{i, t}-R F R_{t}$ is the excess stock returns while $R M_{t}-R F R_{t}$, market premium, measures the market portfolio's value weighted excess returns. The coefficient $\alpha_{i}$ is alpha of the F-F model. $S M B_{t}$ is the size premium, measured by the variations in returns between a small capitalisation portfolio and a large capitalisation portfolio. $H M L_{t}$ is the value premium, measured by the returns' differences between a portfolio of high bookto-market (value) stocks and a portfolio of low book-to-market (growth) stocks. The term $e_{i, t}$ is the residual. In the F-F model, it is estimated the coefficients of $S M B_{t}$ and $H M L_{t}$ to be positive, suggesting that small stocks and value stocks carry higher risks and hence higher expected returns as compared to large stocks and growth stocks.

Starting from January 2001, for the size factor, all stocks listed on the main board of Bursa Malaysia are sorted in descending order according to the values of market capitalisation from December 2000. The stocks are separated into 2 portfolios, that is, small (S) and big (B) market values. This forms the SMB factor. For the book-to-market value (BM) factor, the previously formed two portfolios of small and big market value are further divided into 3 portfolios, respectively, that comprise high $(H)$, medium $(M)$, and low (L). As a result, there are 6 size/BM portfolios produced, i.e. $S / H, S / M, S / L, B / H$, $B / M, B / L$. The value-weighted monthly returns are then estimated over next 12 months for these 6 portfolios and becomes the HML factor. This process of portfolio formation is reformed and repeated each year until December 2015.

For the sake of investigating the dynamic nonlinear association between stock return and 3 risk premiums of the F-F model, we adopt the two-state Markov switching$\operatorname{AR}(p)$ where the specifications echo the original model of Hamilton (1989) but allow the term of constant, slope coefficients to be state-dependent (also known as regimedependent) as follows:

$$
r_{t}=\alpha_{S_{t}}+\beta_{S_{t}} R M_{t}+\delta_{S_{t}} S M B_{t}+\theta_{S_{t}} H M L_{t}+\sum_{i=1}^{P} \rho_{i} r_{t-i}+\varepsilon_{t}, \varepsilon_{t} \approx i . i . d . N\left(0, \sigma^{2}\right)
$$

where $r_{t}$ indicates the excess stock returns, $R M_{t}$ is the market premium, $S M B_{t}$ is the size premium, $H M L_{t}$ is the value premium and $\varepsilon_{t}$ is the innovation process. The state independent autoregressive component with an optimal lag order $p, \operatorname{AR}(p)$, is employed to render the innovation process white noise. While $\beta_{S_{t}}, \delta_{S_{t}}$ and $\theta_{S_{t}}$ are respectively the state-dependent coefficients of market premium, size premium and value premium, $\alpha_{s_{t}}$ is a regime-varying constant term. The unobservable state variable $s_{t}$ is a latent indicator variable which can take only 2 values: either 1 or 2 . It is assumed the state variable observes a first-order Markov chain with a transition probability matrix as follows:

$$
P=\left[\begin{array}{cc}
P^{11} & 1-P^{11} \\
1-P^{22} & P^{22}
\end{array}\right]
$$


where $P^{11}=P\left(S_{t}=1 \mid S_{t-1}=1\right)$ and $P^{22}=P\left(S_{t}=2 \mid S_{t-1}=2\right)$.

These transition probabilities are held to be invariant with time as in the original model of Hamilton. Nevertheless, in order to examine whether the changes in sentiment play a mediating role in the regime switching dynamics between two states of the stock market cycles in Bursa Malaysia, we consider a time-varying transition probability Markov-switching (hereafter TVTP-MS) model, where the transition probabilities are described as follows:

$$
P=\left[\begin{array}{cc}
P^{11}\left(Z_{t}\right) & 1-P^{11}\left(Z_{t}\right) \\
1-P^{22}\left(Z_{t}\right) & P^{22}\left(Z_{t}\right)
\end{array}\right]
$$

where $P^{11}\left(Z_{t}\right)=P\left(S_{t}=1 \mid S_{t-1}=1 Z_{t}\right)$ and $P^{22}\left(Z_{t}\right)=P\left(S_{t}=2 \mid S_{t-1}=2, Z_{t}\right) . Z_{t}$ is the vector of sentiment proxies that affect the likelihood of regime-switching. In our study, we use four specifications of the $Z$ vector, whereby each $Z$ vector includes the lagged values of ADR, CSI, NIPO and RIPO, respectively. In the TVTP-MS model, the transition probability is specified in the following logistic function:

$$
P^{11}\left(Z_{t}\right)=\frac{\exp \left[\sum_{K=0}^{2} \gamma_{1, K} C l_{t-K}\right]}{1+\exp \left[\sum_{K=0}^{2} \gamma_{1, K} C l_{t-K}\right]}
$$

and

$$
P^{22}\left(Z_{t}\right)=\frac{\exp \left[\sum_{K=0}^{2} \gamma_{2, K} C l_{t-K}\right]}{1+\exp \left[\sum_{K=0}^{2} \gamma_{2, K} C l_{t-K}\right]}
$$

Due to the presence of two regimes or states, we obtain two separate estimates of $\gamma$ - one for each regime. The regimes-switching probabilities are allowed to be varying over time with the changes in investor sentiment, which are represented by four market sentiment proxies.

\section{Results and Discussions}

\subsection{Descriptive Statistics}

Table 1 summarises descriptive statistics of stock excess returns ( $r$ ), market premium $(\mathrm{RM})$, size premium $(\mathrm{SMB})$, value premium $(\mathrm{HML})$ and four market sentiment proxies. Two variables of sentiment proxies (i.e. ADR and CSI) are transformed into logarithmic form to compress the scale. Interestingly, the stock excess returns exhibit the mean value below zero with the minimum of -22.935 and the maximum of 12.290 for the sample period from January 2001 to December 2015. While the mean values of 
Table 1. Summary statistics

\begin{tabular}{lcccccccc}
\hline & $\mathrm{r}$ & $\mathrm{RM}$ & $\mathrm{SMB}$ & $\mathrm{HML}$ & $\mathrm{ADR}$ & $\mathrm{CSI}$ & $\mathrm{NIPO}$ & $\mathrm{RIPO}$ \\
\hline Mean & -2.727 & -2.398 & -0.088 & 0.938 & 0.097 & 4.635 & 2.311 & 0.025 \\
Maximum & 12.290 & 10.770 & 9.765 & 14.047 & 1.798 & 4.821 & 13.000 & 3.782 \\
Minimum & -22.935 & -20.110 & -4.823 & -6.166 & -4.112 & 4.156 & 0.000 & -0.976 \\
Std. Dev. & 5.323 & 4.231 & 2.282 & 2.688 & 0.991 & 0.148 & 2.430 & 0.633 \\
Skewness & -0.406 & -0.500 & 0.744 & 0.663 & -1.206 & -1.472 & 1.838 & 1.830 \\
Kurtosis & 4.674 & 5.054 & 4.550 & 5.523 & 5.762 & 4.333 & 7.268 & 10.199 \\
Jarque-Bera & $25.965^{* * *}$ & $39.131^{* * *}$ & $34.628^{* * *}$ & $60.949^{* * *}$ & $100.824^{* * *}$ & $78.319^{* * *}$ & $237.944^{* * *}$ & $489.119^{* * *}$ \\
Observations & 180 & 180 & 180 & 180 & 180 & 180 & 180 & 180 \\
\hline
\end{tabular}

Note: ${ }^{* * *}$ denotes significance at 1 percent level.

the RM and SMB are negative, the remainder show a positive value. Kurtosis is the measurement of the "fatness" for a tail distribution. All the series display a positive excess kurtosis (i.e., leptokurtic distribution) over the sample period. This implies that all the series' distributions have higher peaks around the mean than normal distribution, which causes thick tails on both sides of the distribution. The $r, R M, A D R$ and $\mathrm{CSI}$ series indicate negative skewness while SMB, HML and another two sentiment proxies (NIPO and RIPO) series indicate positive skewness. In addition, Jarque-Bera statistic denotes the goodness-of-fit on whether the sample data has the skewness and kurtosis to match a normal distribution. From Table 1, the Jarque-Bera statistic signifies that the normality test is rejected at 1 percent significance level for all the series during the sample period.

\subsection{Estimation and Diagnostics}

We begin our empirical analysis by first testing whether the TVTP-MS model with inclusion of four separate market sentiment proxies (i.e. ADR, NIPO, CSI and RIPO) in its transition equation provides a better characterisation of the stock returns in Bursa Malaysia than the linear model and the Markov switching model with fixed regime transition probabilities (FTP-MS). For the specifications of both the TVTP-MS and FTP-MS models, in accordance with the Akaike Information Criterion (AIC) and Schwarz Criterion (SBC), we use TVTP-MS AR(4) specification, which is found to be adequate to make the residuals white noise, for ADR and NIPO. Meanwhile, for CSI and RIPO, the specification of TVTP-MS AR (3) is chosen. Besides, the number of lags $K$ for estimates of $\gamma$ (i.e. four market sentiment proxies) is also selected based on the Akaike Information Criterion (AIC) and Schwarz Criterion (SC). While the ADR and NIPO enter the transaction equation with 2 months lag, there is a 1 month lag for both CSI and RIPO. Our models are in line with Schmeling's (2009) study where the author investigated the relation between investor sentiment and future stock returns for 18 industrialised countries and found that the predictive power of sentiment was most pronounced for short-term horizons of 1 to 6 months. 
Comparison among three models using model selection criteria is reported in Tables A1, A2, A3 and A4 (see Appendix) for the four market sentiment proxies respectively. All the model selection criteria conclude that TVTP-MS model is more superior to both the linear and the FTS-MS models across four market sentiment proxies. In addition, Table 2 shows that the data intensely rejects at 1 percent significance level the linear model in favour of the TVTP-MS model for all the panels, in accordance with standard Likelihood Ratio (LR) test.

As the sample is dichotomising into regimes that show increasing stock excess returns and decreasing stock excess returns, the Markov-switching models are able to identify two regimes which can be labelled as low mean (i.e. bear market) and high mean (i.e. bull market) in which the effects of three risk factors (RM, SMB and $H M L$ ) of the F-F model on the stock excess returns differ significantly, as exhibited in Table 2. Interestingly, the two mean regimes identified by the model show negative values but differences in the magnitude. The negativity of the mean is in agreement with the results of Lai et al. (2013) in their examination of the F-F model in Bursa Malaysia between January 1996 and December 2005.

The estimation results in Table 2 show that on the whole all the sentiment proxies, with the only exception of RIPO, do somewhat affect the probabilities of switching between regimes. Specifically, the sentiment proxy of NIPO has exerted an influence on both regime transition probabilities of the bull and the bear markets. Meanwhile, ADR and $\mathrm{CSI}$ are seen to affect only the regime transition probabilities of the bull market and the bear market, respectively.

In high mean regime (i.e. bull market), all the separate sentiment proxies' coefficients $(\gamma)$ are positive, implying that increases in investors' positive sentiment would raise the probability of being in the high mean regime (i.e. bull market). Conversely, the negative coefficient of $\gamma$ as exhibited by all the sentiment proxies in the regime of low mean (i.e. bear market) signifies that an increase in investors' positive sentiment would cause a decline in the probability of being in the low mean regime (i.e. bear market). When comparing the absolute values of the coefficients of $\gamma$ for all the sentiment proxies between the high mean regime (i.e. bull market) and low mean regime (i.e. bear market), it is revealed that the latter is higher than the former. The result implies that when there is an increase in positive sentiment of the investors, the probability of the stock returns moving from bear market into bull market is higher than the probability of the stock returns staying in the bull market. In other words, an increase in positive sentiment of investors leads to a higher transition probability of regime switching during bear market.

For the estimated market premiums as shown in Panels $A$ to $D$ in Table 2, the positive market premiums are not only in line with the conventional empirical results of the F-F model but also varying with time. The estimated market premiums in the bull market are significantly larger than that of the bear market. Besides, the market premiums shown in the four panels are all greater than one in the bull market, implying that the stock prices in the Bursa Malaysia encounter higher volatility than the market portfolio index.

With regard to the estimation results of size premium, the size premiums are positive and significant in both regimes, consistent with the line of reasoning in the 
Table 2. TVTP-MS model results (with four market sentiment proxies in the separate transition equation)

\begin{tabular}{|c|c|c|c|c|}
\hline \multicolumn{3}{|c|}{$\begin{array}{l}\text { Panel A: ADR } \\
\text { TVTP-MS-AR(4) model }\end{array}$} & \multicolumn{2}{|c|}{$\begin{array}{l}\text { Panel B: NIPO } \\
T V T P-M S-A R(4) \text { model }\end{array}$} \\
\hline & $\begin{array}{l}\text { Regime 1: } \\
\text { High mean }\end{array}$ & $\begin{array}{l}\text { Regime 2: } \\
\text { Low mean }\end{array}$ & $\begin{array}{l}\text { Regime 1: } \\
\text { High mean }\end{array}$ & $\begin{array}{l}\text { Regime 2: } \\
\text { Low mean }\end{array}$ \\
\hline Parameters & Estimate & Estimate & Estimate & Estimate \\
\hline$\alpha$ & $-0.47(0.24)^{*}$ & $-1.85(0.35)^{* * *}$ & $-0.72(0.33)^{* *}$ & $-1.34(0.29)^{* * *}$ \\
\hline$\beta_{R M}$ & $1.01(0.05)^{* * *}$ & $0.70(0.08)^{* * *}$ & $1.00(0.07)^{* * *}$ & $0.79(0.06)^{* * *}$ \\
\hline$\delta_{S M B}$ & $0.40(0.08)^{* * *}$ & $1.37(0.18)^{* * *}$ & $0.27(0.15)^{*}$ & $0.88(0.10)^{* * *}$ \\
\hline$\theta_{H M L}$ & $0.41(0.08)^{* * *}$ & $0.63(0.13)^{* * *}$ & $0.24(0.09)^{* *}$ & $0.74(0.09)^{* * *}$ \\
\hline$\rho_{1}$ & & & & \\
\hline$\rho_{2}$ & & & & \\
\hline$\rho_{3}$ & & & & \\
\hline$\rho_{4}$ & & & & \\
\hline$\sigma$ & & & & \\
\hline \multicolumn{5}{|c|}{ Regime parameters } \\
\hline$\gamma\left(A D R_{t-2}\right)$ & $2.50(1.08)^{* *}$ & $-8.61(11.52)$ & & \\
\hline$\gamma\left(N I P O_{t-2}\right)$ & & & $0.46(0.26)^{*}$ & $-0.57(0.32)^{*}$ \\
\hline Log-likelihood & & & & \\
\hline LR test & & & & \\
\hline J-B & & & & \\
\hline $\mathrm{Q}(10)$ & & & & \\
\hline$Q^{2}(10)$ & & & & \\
\hline \multicolumn{3}{|l|}{ Panel C: CSI } & \multicolumn{2}{|l|}{ Panel D: RIPO } \\
\hline & $\begin{array}{l}\text { Regime 1: } \\
\text { High mean }\end{array}$ & $\begin{array}{l}\text { Regime 2: } \\
\text { Low mean }\end{array}$ & $\begin{array}{l}\text { Regime 1: } \\
\text { High mean }\end{array}$ & $\begin{array}{l}\text { Regime 2: } \\
\text { Low mean }\end{array}$ \\
\hline Parameters & Estimate & Estimate & Estimate & Estimate \\
\hline$\alpha$ & $-0.32(0.18)^{*}$ & $-1.57(0.41)^{* * *}$ & $-0.34(0.33)$ & $-1.54(0.38)^{* * *}$ \\
\hline$\beta_{R M}$ & $1.07(0.06)^{* * *}$ & $0.69(0.08)^{* * *}$ & $1.08(0.07)^{* * *}$ & $0.69(0.08)^{* * *}$ \\
\hline$\delta_{S M B}$ & $0.44(0.09)^{* * *}$ & $1.40(0.18)^{* * *}$ & $0.41(0.10)^{* * *}$ & $1.25(0.17)^{* * *}$ \\
\hline$\theta_{H M L}$ & $0.52(0.09)^{* * *}$ & $0.59(0.10)^{* * *}$ & $0.41(0.14)^{* * *}$ & $0.60(0.09)^{* * *}$ \\
\hline$\rho_{1}$ & & & & \\
\hline$\rho_{2}$ & & & & \\
\hline$\rho_{3}$ & & & & \\
\hline$\sigma$ & & & & \\
\hline
\end{tabular}


Table 2. Continued

\begin{tabular}{|c|c|c|c|c|}
\hline \multicolumn{3}{|c|}{$\begin{array}{l}\text { Panel C: CSI } \\
T V T P-M S-A R(3) \text { model }\end{array}$} & \multicolumn{2}{|l|}{$\begin{array}{l}\text { Panel D: RIPO } \\
\text { TVTP-MS-AR(3) model }\end{array}$} \\
\hline & $\begin{array}{l}\text { Regime 1: } \\
\text { High mean }\end{array}$ & $\begin{array}{l}\text { Regime 2: } \\
\text { Low mean }\end{array}$ & $\begin{array}{l}\text { Regime 1: } \\
\text { High mean }\end{array}$ & $\begin{array}{l}\text { Regime 2: } \\
\text { Low mean }\end{array}$ \\
\hline Parameters & Estimate & Estimate & Estimate & Estimate \\
\hline \multicolumn{3}{|c|}{ Regime parameters } & \multirow{7}{*}{$0.21(1.09)$} & \multirow{8}{*}{$-1.01(1.12)$} \\
\hline$\gamma\left(C S I_{t-1}\right)$ & $2.56(3.19)$ & $-28.46(11.81)^{* *}$ & & \\
\hline$\gamma\left(R I P O_{t-1}\right)$ & & & & \\
\hline Log-likelihood & & -369.22 & & \\
\hline LR test & & $62.16[0.00]^{* * *}$ & & \\
\hline J-B & & $1.42[0.49]$ & & \\
\hline $\mathrm{Q}(10)$ & & $10.47[0.16]$ & & \\
\hline$Q^{2}(10)$ & & $10.84[0.37]$ & $7.45[0.68]$ & \\
\hline
\end{tabular}

Notes: J-B stands for the Jarque-Bera normality test, $Q(10)$ and $Q^{2}(10)$ indicates the Box-Pierce serial correlation test for residuals and squared residuals, respectively. Figures in parentheses and square brackets are standard errors and $\rho$-values, respectively. ${ }^{* * *},{ }^{*}$ and $*$ denote statistical significance at $1 \%, 5 \%$ and $10 \%$ levels, respectively. The number of lag $K$ for estimates of $\gamma$ is selected based on the Akaike Information Criterion (AIC) and Schwarz Criterion (SC).

F-F model that small capitalisation stocks generate bigger returns than those of large capitalisation. The estimated size premiums are also found to be time-varying instead of time-invariant. Additionally, the results show that small firms seem to be able to obtain more size premium in the low mean regime (i.e. bear market) compared to the high mean regime (i.e. bull market). It is probably justifiable that in the midst of a negative market sentiment in the bear market, small firms are able to adjust their operational strategies more swiftly and easily than large firms.

The value premiums exhibited in Table 2 are all significantly positive in both regimes, in line with the standard empirical analyses of F-F model and most of its advocates that value stocks (which are of more wholesome operating structure and system) generate higher returns than growth stocks. Again, the value premiums are seen to be time-varying. Interestingly, the results of the estimated value premium show that the value premiums are increasing in the low mean regime (i.e. bear market). To put it simply, investors are more attracted to the value stocks in the situation of negative market sentiment during the bear market.

Figure 1 plots the filtered transition probabilities for TVTP-MS model with inclusion of four separate market sentiment proxies in its transition equation in the low mean regime (i.e. bear market). When the probabilities are above 0.5 , the Bursa Malaysia is more likely to be in a bear market and vice versa. As noticed in Figure 1, the TVTP-MS model is able to well capture some major and critical episodes in the regional or global economy such as the 2003 Iraq war, the 9.3 magnitude earthquake in Southeast Asia in December 2004, the 2007-2009 Global Financial Crisis (GFC) as well as the 2011-2012 European Sovereign Debt Crisis. 

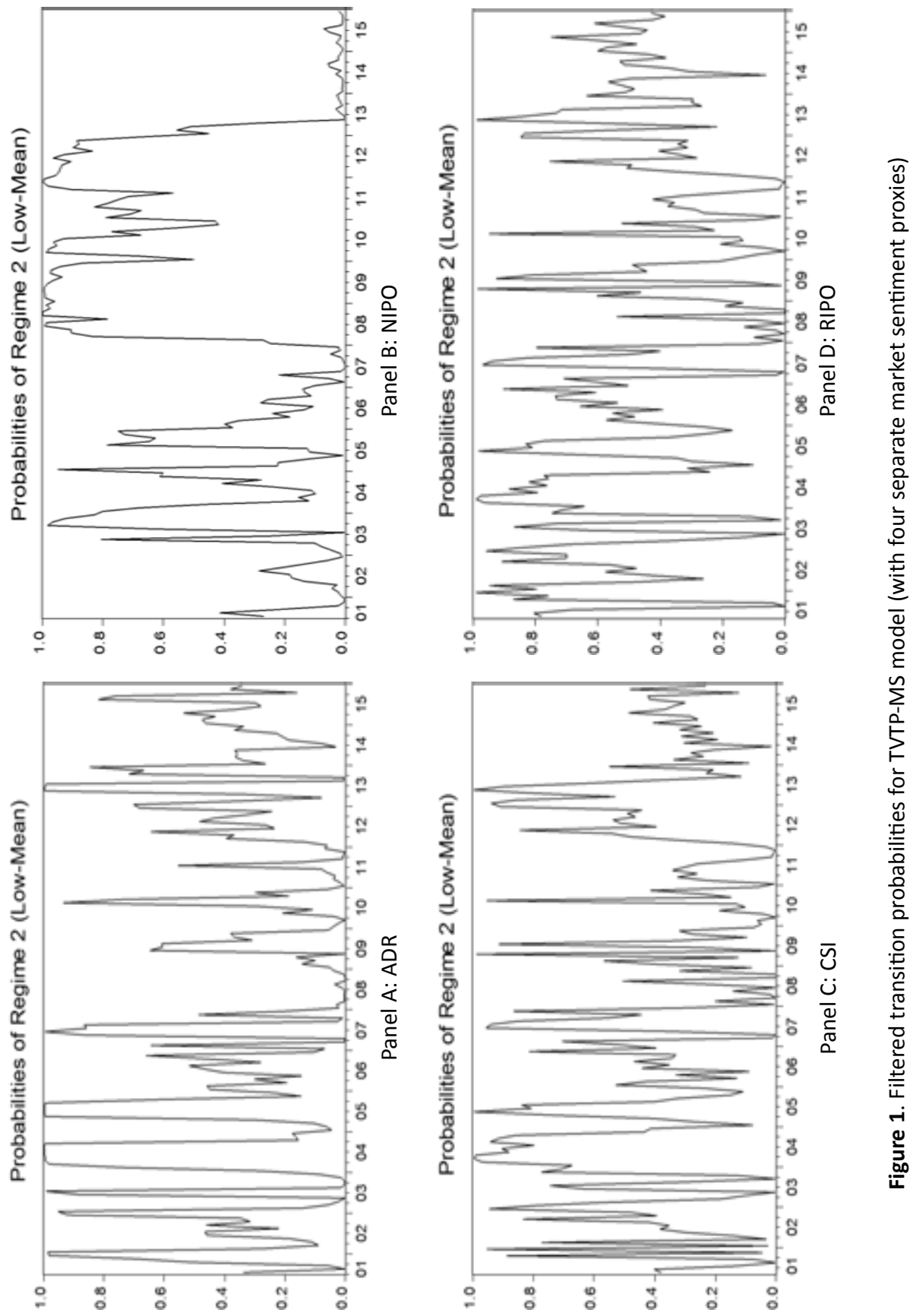


\section{Conclusion}

In this study, we empirically look into the nonlinear effects of investor sentiment on asset pricing in Bursa Malaysia. In particular, we employ two-state TVTP-MS model for re-examining the F-F model's three risk premiums when four different market sentiment proxies are utilised as a mediator of regime switches. To the best of our knowledge, our study is the first in Malaysian literature to focus explicitly on the role of investor sentiment using market sentiment proxies individually in explaining stock market regimes and regime switches.

On the whole, all the model selection criteria conclude that the two-state TVTP-MS model is more superior to both the linear and the FTS-MS models across four market sentiment proxies. The empirical results of the TVTP-MS model indicate that to some extent changes in sentiment play a mediating role in the regimes-switching dynamics betweenbear and bull market cycles in Malaysian stock returns. Moreover, our study shows that an increase in positive sentiment of investors would result in a higher transition probability of regime switching during bear markets. It is also found that the lead times from the four market sentiment proxies to the stock returns in Bursa Malaysia are on average within one to two months.

In addition, the results from our TVTP-MS model illustrate that the F-F model's three risk premiums are time-varying. The market premium falls as the stock market switches from bull to bear periods. On the contrary, both the size and value premiums increase when the stock market moves from bull to bear periods. It is therefore well advised that investors in Bursa Malaysia should adjust their investment portfolios contingent on each period's estimated risk premiums.

\section{References}

Ali, N., Nassir, A.M., Hassan, T., \& Abidin, S.Z. (2010). Short run stock overreaction: Evidence from Bursa Malaysia. International Journal of Economics and Management, 4(2), 319-333.

Angabini, A., \& Wasiuzzaman, S. (2010). GARCH models and the financial crisis - a study of the Malaysia stock markets. International Journal of Applied Economics and Finance, 5(3), 226236. https://doi.org/10.3923/ijaef.2011.226.236

Baker, M., \& Wurgler, J. (2006). Investor sentiment and the cross-section of stock returns. Journal of Finance, 61(4), 1645-1680. https://doi.org/10.1111/j.1540-6261.2006.00885.x

Baker, M., \& Wurgler, J. (2007). Investor sentiment in the stock market. Journal of Economic Perspectives, 21(2), 129-152. https://doi.org/10.1257/jep.21.2.129

Baker, M., Wurgler, J., \& Yuan, Y. (2012). Global, local and contagious investor sentiment. Journal of Financial Economics, 104(2), 272-287. https://doi.org/10.1016/j.jfineco.2011.11.002

Brown, G.W., \& Cliff, M.T. (2004). Investor sentiment and the near-term stock market. Journal of Empirical Finance, 11(1), 1-27. https://doi.org/10.1016/j.jempfin.2002.12.001

Chen, S-S. (2011). Lack of consumer confidence and stock returns. Journal of Empirical Finance, 18(2), 225-236. https://doi.org/10.1016/j.jempfin.2010.12.004

Chen, M-P., Chen, P-F., \& Lee, C-C. (2013). Asymmetric effects of investor sentiment on industry stock returns: Panel data evidence. Emerging Markets Review, 14(March), 35-54. https://doi. org/10.1016/j.ememar.2012.11.001

Chen, X., Tian, Y., \& Zhao, R. (2017). Study of the cross-market effects of Brexit based on the improved symbolic transfer entropy GARCH model - An empirical analysis of stock-bond correlations. PLOS ONE, 12(8): e0183194. https://doi.org/10.1371/journal.pone.0183194 
De Long, J.B., Shleifer, A., Summers, L.H., \& Waldmann, R.J. (1990). Noise trader risk in financial markets. Journal of Political Economy, 98(4), 703-738. https://doi.org/10.1086/261703

Fama, E.F., \& French, K.R. (1993). Common risk factors in the returns on stocks and bonds. Journal of Financial Economics, 33(1), 3-56. https://doi.org/10.1016/0304-405X(93)90023-5

Fama, E.F., \& French, K.R. (1995). Size and book-to-market factors in earnings and returns. Journal of Finance, 50(1), 131-155. https://doi.org/10.1111/j.1540-6261.1995.tb05169.x

Fama, E.F., \& French, K.R. (2012). Size, value, and momentum in international stock returns. Journal of Financial Economics, 105(3), 457-472. https://doi.org/10.1016/j.jfineco. 2012.05.011

Fama, E.F., \& French, K.R. (2015). A five-factor asset pricing model. Journal of Financial Economics, 116(1), 1-22. https://doi.org/10.1016/j.jfineco.2014.10.010

Fisher, K.L., \& Statman, M. (2003). Consumer confidence and stock returns. Journal of Portfolio Management, 30(1), 115-127. https://doi.org/10.3905/jpm.2003.319925

Hamilton, J.D. (1989). A new approach to the economic analysis of nonstationary time series and the business cycle. Econometrica, 57(2), 357-384. https://doi.org/10.2307/1912559

Harshita, Singh, S., \& Yadav, S.S. (2015). Indian stock market and the asset pricing models. Procedia Economics and Finance, 30, 294-304. https://doi.org/10.1016/S2212-5671(15) 01297-6

Ho, C., \& Hung, C-H. (2009). Investor sentiment as conditioning information in asset pricing. Journal of Banking \& Finance, 33(5), 892-903. https://doi.org/10.1016/j.jbankfin.2008.10.004

Ho, J.C., \& Hung, C-H. (2012). Predicting stock market returns and volatility with investor sentiment: Evidence from eight developed countries. Journal of Accounting and Finance, 12(4), 49-66. https://doi.org/10.2139/ssrn.2279339

Hsu, C-C., Lin, H-Y., \& Wu, J-Y. (2011). Consumer confidence and stock markets: The panel causality evidence. International Journal of Economics and Finance, 3(6), 91-99. https://doi. org/10.5539/ijef.v3n6p91

Idris, A.N., \& Aziz, A. (2016, December 8). Jomo: Ringgit's fall also due to loss of confidence in government. The Edge Financial Daily.

Jansen, W.J., \& Nahuis, N.J. (2003). The stock market and consumer confidence: European evidence. Economics Letters, 79(1), 89-98. https://doi.org/10.1016/S0165-1765(02)00292-6

Karakatsani, N.V., \& Salmon, M.H. (2008). Sentiment and price formation: Interactions and regime shifts (SSRN working paper series). https://doi.org/10.2139/ssrn.1102209

Kim, T., \& Ha, N. (2010). Investor sentiment and market anomalies. 23rd Australasian Finance and Banking Conference 2010 Paper (SSRN working paper series). https://doi.org/10.2139/ ssrn. 1663649

Kubota, K., \& Takehara, H. (2017). Does the Fama and French Five-Factor model work well in Japan? International Review of Finance, 18(1), 137-146. https://doi.org/10.1111/irfi.12126

Kuhnen, C.M., \& Knutson, B. (2011). The influence of affect on beliefs, preferences and financial decision. Journal of Financial and Quantitative Analysis, 46(3), 605-626. https://doi.org/ $10.1017 / \mathrm{S} 0022109011000123$

Kumar, A., \& Lee, C. (2006). Retail investor sentiment and return comovements. Journal of Finance, 61(5), 2451-2486. https://doi.org/10.1111/j.1540-6261.2006.01063.x

Lai, M.M., Tan, S.H., \& Chong, L.L. (2013). The behavior of institutional and retail investors in Bursa Malaysia during the bulls and bears. Journal of Behavioral Finance, 14(2), 104-115. https://doi.org/10.1080/15427560.2013.790822

Lawrence, E.R., Geppert, J., \& Prakash, A.J. (2007). Asset pricing models: A comparison. Applied Financial Economics, 17(11), 933-940. https://doi.org/10.1080/09603100600892863

Lee, Charles M.C., Shleifer, A., \& Thaler, R.H. (1991). Investor sentiment and the closed-end fund puzzle. Journal of Finance, 46(1), 75-109. https://doi.org/10.1111/j.1540-6261.1991. tb03746.x 
Lee, C.C., \& Chiu, Y.B. (2012). The impact of real income on insurance premiums: Evidence from panel data. International Review of Economics \& Finance, 21(1), 246-260. https://doi. org/10.1016/j.iref.2011.07.003

Liao, T-L., Huang, C-J., \& Wu, C-Y. (2011). Do fund managers herd to counter investor sentiment? Journal of Business Research, 64(2), 207-212. https://doi.org/10.1016/j.jbusres.2010.01.007

Lintner, J. (1965). Security prices, risk, and maximal gains from diversification. Journal of Finance, 20(4), 587-615. https://doi.org/10.1111/j.1540-6261.1965.tb02930.x

McMillan, D.G. (2003). Non-linear predictability of UK stock market returns. Oxford Bulletin of Economics and Statistics, 65(5), 557-573. https://doi.org/10.1111/j.1468-0084.2003.00061.x

Reinganum, M.R. (1981). A new empirical perspective on the CAPM. Journal of Financial and Quantitative Analysis, 16(4), 439-462. https://doi.org/10.2307/2330365

Rosenberg, B., Reid, K., \& Lanstein, R. (1985). Persuasive evidence of market inefficiency. Journal of Portfolio Management, 11(3), 9-16. https://doi.org/10.3905/jpm.1985.409007

Schmeling, M. (2009). Investor sentiment and stock returns: Some international evidence. Journal of Empirical Finance, 16(3), 394-408. https://doi.org/10.1016/j.jempfin.2009.01.002

Sharpe, W.F. (1964). Capital asset prices: A theory of market equilibrium under conditions of risk. Journal of Finance, 19(3), 425-442. https://doi.org/10.2307/2977928

Shefrin, H., \& Statman, M. (1994). Behavioral capital asset pricing theory. Journal of Financial and Quantitative Analysis, 29(3), 323-349. https://doi.org/10.2307/2331334

Simpson, M.W., \& Ramchander, S. (2008). An inquiry into the economic fundamentals of the Fama and French equity factors. Journal of Empirical Finance, 15(5), 801-815. https://doi. org/10.1016/j.jempfin.2008.02.003

Statman, M., Fisher, K.L., \& Anginer, D. (2008). Affect in a behavioral asset-pricing model. Financial Analysts Journal, 64(2), 20-29. https://doi.org/10.2469/faj.v64.n2.8

$\mathrm{Xu}$, Y.H., \& Green, C.J. (2013). Asset pricing with investor sentiment: Evidence from Chinese stock markets. Manchester School, 81(1), 1-32.https://doi.org/10.1111/j.1467-9957.2011.02260.x

Yang, C., \& Zhang, R. (2014). Does mixed-frequency investor sentiment impact stock returns? Based on the empirical study of MIDAS regression model. Applied Economics, 46(9), 966-972. https://doi.org/10.1080/00036846.2013.864041

Yang, C.P., \& Li, J.F. (2013). Investor sentiment, information and asset pricing model. Economic Modelling, 35(September), 436-442.https://doi.org/10.1016/j.econmod.2013.07.015

Zhang, W., \& Semmler, W. (2009). Prospect theory for stock markets: Empirical evidence with time-series data. Journal of Economic Behavior and Organization, 72(3), 835-849.https://doi. org/10.1016/j.jebo.2009.08.003 


\section{Appendix}

Table A1. A comparison of models via model selection criteria for stock returns in Bursa Malaysia

\begin{tabular}{lccc}
\hline & Linear model & FTP-MS AR(4) & TVTP-MS AR(4) with ADR \\
\hline Log-likelihood & -403.8853 & -366.9890 & $-357.4154^{*}$ \\
AIC & 4.587614 & 4.340784 & $4.254721^{*}$ \\
SBC & 4.747262 & 4.610996 & $4.560961^{*}$ \\
HQ & 4.652344 & 4.450380 & $4.378930^{*}$
\end{tabular}

Note: * The best model with relatively small AIC/SBC/HQ but relatively high log-likelihood. The TVTP-MS model specification and the estimatesare reported in Panel A, Table 2. The estimates for both the FTP-MS and the linear models are available upon request.

Table A2. A comparison of models via model selection criteria for stock returns in Bursa Malaysia

\begin{tabular}{lccc}
\hline & Linear model & FTP-MS AR(4) & TVTP-MS AR(4) with NIPO \\
\hline Log-likelihood & -403.8853 & -366.9890 & $-357.7290^{*}$ \\
AIC & 4.587614 & 4.340784 & $4.258284^{*}$ \\
SBC & 4.747262 & 4.610996 & $4.564524^{*}$ \\
HQ & 4.652344 & 4.450380 & $4.382493^{*}$
\end{tabular}

Note: * The best model with relatively small AIC/SBC/HQ but relatively high log-likelihood. The TVTP-MS model specification and the estimates are reported in Panel B, Table 2 . The estimates for both the FTP-MS and the linear models are available upon request.

Table A3. A comparison of models via model selection criteria for stock returns in Bursa Malaysia

\begin{tabular}{lccc}
\hline & Linear model & FTP-MS AR(3) & TVTP-MS AR(3) with CSI \\
\hline Log-likelihood & -403.8898 & -381.2864 & $-369.2201^{*}$ \\
AIC & 4.576554 & 4.466513 & $4.352769^{*}$ \\
SBC & 4.718463 & 4.717734 & $4.639879^{*}$ \\
HQ & 4.634092 & 4.568399 & $4.469210^{*}$ \\
\hline
\end{tabular}

Note: * The best model with relatively small AIC/SBC/HQ but relatively high log-likelihood. The TVTP-MS model specification and the estimates are reported in Panel C, Table 2. The estimates for both the FTP-MS and the linear models are available upon request.

Table A4. A comparison of models via model selection criteria for stock returns in Bursa Malaysia

\begin{tabular}{lccc}
\hline & Linear model & FTP-MS AR(3) & TVTP-MS AR(3) with RIPO \\
\hline Log-likelihood & -403.8898 & -381.2864 & $-369.9547^{*}$ \\
AIC & 4.576554 & 4.466513 & $4.325144^{*}$ \\
SBC & 4.718463 & 4.717734 & $4.648180^{*}$ \\
HQ & 4.634092 & 4.568399 & $4.477511^{*}$ \\
\hline
\end{tabular}

Note: * The best model with relatively small AIC/SBC/HQ but relatively high log-likelihood. The TVTP-MS model specification and its estimates are reported in Panel D, Table 2. The estimates for both the FTP-MS and the linear models are available upon request. 